\title{
Educación social en la Organización Minuto de Dios. Tras las huellas de un sueño ${ }^{2}$
}

\author{
Social Education in the "Organizacion Minuto de Dios". \\ Behind the Footprints of a Dream
}

\begin{abstract}
Resumen
El Minuto de Dios se ha declarado como una obra de carácter social y educativa que ha procurado el desarrollo integral de las comunidades, creada por el padre Rafael García Herreros. Con base en lo anterior y en la búsqueda de nuevos elementos que den cuenta de la propuesta educativa de la obra Minuto de Dios, el proyecto de investigación que se describe de manera general en este artículo pretende revisar la concepción que existe sobre la educación social. La pregunta: ¿Cuál es la concepción que se tiene sobre la educación social en los pregrados de la Facultad de Educación, en las Facultades de la sede principal de Uniminuto y en las instituciones de educación básica y media de la organización Minuto de Dios? es el eje orientador de la investigación. El diseño metodológico se basa en la investigación documental y pretende reconocer la manera como se concibe la educación social en el contexto de la Organización Minuto de Dios.
\end{abstract}

Palabras clave: Educación social, pedagogía social, pedagogía praxeológica, investigación documental.

\begin{abstract}
"El Minuto de Dios" has been declared as a work of social and educative character that has supported the integral development of communities and it was created by the priest Rafael Garcia Herreros. According to this and the search of new components that give an account of the educative proposal of "Minuto de Dios", the research project attempts to revise the inner conception that exist over social education at undergraduate programs of School of education and the schools of Uniminuto (University headquarters) and in the basic and media institutions of the "Corporación Minuto de Dios". The methodological design is based on documentary research and attempts to recognize how social education is understood in the context of "Organización Minuto de Dios".
\end{abstract}

Keywords: Social education, social pedagogy, praxeological pedagogy, documentary research.

\section{Recibido: 2 de mayo de 2014, evaluado: 3 de junio de 2014, aprobado: 16 de junio de 2014}

1 Docente de planta de la Universidad Distrital Francisco José de Caldas, investigador en la Facultad de Educación de Uniminuto. Candidato a Doctor del Doctorado Interinstitucional en Educación de la Universidad Distrital Francisco José de Caldas, Universidad Pedagógica Nacional y Universidad del Valle. Sergiobri2012@gmail.com

2 Articulo que resulta de un ejercicio reflexivo sobre la investigación "La educación social en la organización Minuto de Dios", que se propone indagar acerca de la concepción de educación social en esta obra. Este ejercicio se plantea teniendo en cuenta la perspectiva praxeológica que orienta el modelo educativo de Uniminuto, consistente en evaluar de manera crítica y permanentemente los procesos investigativos y formativos. 


\section{El inicio de una visión social}

La visionaria misión de la Organización Minuto de Dios en manos del Padre García Herreros fue difundida en todo el país aproximadamente desde 1950, reconociéndose como una labor dirigida a la generación de oportunidades para las comunidades más necesitadas.

El minuto de Dios, concreción de este pensamiento comunitarista no violento, aparece como un modelo social alternativo y de construcción comunitaria que se plantea como una opción, un experimento microsocial, para una Nación de poca participación y mucha exclusión (Juliao, 2007, p. 189).

El modelo de comunidad del Minuto de Dios se orienta por los principios de una sociedad inclusiva y participante, donde los sujetos son reconocidos desde su individualidad, pero también en su condición de seres sociales; en ese sentido, no hay distingo de razas ni condición socio-económica que pueda condicionar la forma como se hace posible una vida digna y solidaria al servicio de los demás.

El Padre García Herreros, visionario de la idea de comunidad, enrumbó su obra hacia el pluralismo social, la participación y la igualdad desde la más sincera humildad y preocupación por los demás, configurando así una intención de comunidad solidaria, sostenible y autogestionada.

De acuerdo con Cano (1960, citado por Juliao, 2007) el sueño de Rafael García Herreros era, según sus propias palabras:

Lograr la plenitud humana y temporal de una comunidad de gentes que no son ni extraordinarias ni superdotadas. Es fácil conseguirlo con sabios y santos, pero necesitamos hacerlo con personas corrientes, del común. El nuestro es un ensayo que busca la vida plena sin apostatar de lo fundamental de la existencia (p. 157).

Lo que implica, de alguna manera, un deseo profundo por difundir y masificar el sentido de lo humano, presente en las relaciones que se tejen permanentemente en los contextos sociales, rescatando así el valor de la acción del sujeto en su contexto, en el cual incide y del cual recibe los insumos necesarios para una vida plena.

La razón de ser de la obra Minuto de Dios se fundamenta en los principios cristianos del evangelio y en el reconocimiento de abanderar procesos de gestión humana que permitan avanzar en la equidad e igualdad de oportunidades, que trasciendan las dinámicas sociales individualistas y utilitaristas. Un sueño y una visión que se teje en el hacer cotidiano y en los proyectos que se han ido forjando en diferentes ámbitos entre los que está el educativo y en el cual se centran las reflexiones de este artículo.

Desde el ámbito educativo, su visión de Universidad soñada estuvo encaminada a no seguir prototipos, a innovar, a exigirse cada vez más, a cambiar mentalidades, a proveer oportunidades para los ciudadanos y ciudadanas que necesita el país, jóvenes creativos, analíticos, críticos y propositivos. Siendo este el escenario que permite considerar los elementos generales de la educación social implícita en el modelo de formación del Minuto de Dios.

Cabe preguntarse: ¿Qué es lo que caracteriza a la educación social?, ‘acaso toda educación no es social? En el contexto donde se desarrollan las discusiones acerca de la educación social, se plantea que se educa para la participación social y para asegurar el ejercicio de derechos y libertades. La Organización Minuto de Dios, a través de Uniminuto y de las instituciones educativas de básica y media, ha venido trabajando en la promoción del desarrollo humano y social. Es, por tanto, de vital importancia reflexionar de manera crítica sobre la educación social que se gesta en las dinámicas de trabajo educativo planteadas, analizar sus implicaciones y su impacto en el ámbito nacional e internacional y la forma como ello retroalimenta y fortalece la visión de lo social que propende el Minuto de Dios. 
¿Qué puede decirse inicialmente acerca de la educación social? Según Quintana Cabanas (citado por Pérez Serrano, 2003) la educación social tiene por objeto el logro de la madurez social de cada persona, entendiéndose como un aspecto importante de la educación general del ser humano. La formación para la correcta socialización implica la formación cívico-democrática y para la ciudadanía. Se trata de una educación para el desarrollo de valores sociales, orientada al fomento del comportamiento democrático de todos los ciudadanos, así como al compromiso de construir la sociedad.

Se afirma además que la educación social debe preocuparse por las dificultades escolares, aportando al reconocimiento de sus problemas a la sociedad. De igual manera, la escuela debe ocuparse de la educación social porque en ella debe hablarse también de los conflictos sociales, la influencia de la televisión, la situación de marginación y desequilibrio social, la violencia, las tribus urbanas y el tema de la delincuencia y la drogadicción, entre otros. $\mathrm{La}$ integralidad de la función de la educación social y la promoción de las personas en un contexto mediado por una intención de formación específica permite el desarrollo de profesionales que se insertan con perspectivas de participación al ámbito laboral, incorporándose al contexto social de manera activa y transformadora.

De acuerdo a lo anterior, la educación social es el reencuentro con el verdadero significado de la educación y ésta, como la pedagogía social, son una respuesta a la pérdida de sentido humano y social en un contexto contemporáneo de transformaciones aceleradas. Por tanto, el abordaje del análisis de la realidad y la participación con un rol protagónico en su construcción es tarea a desarrollarse de manera plena y urgente. Por eso, la pedagogía social debe ser comprendida como producción de nuevos conocimientos sobre el vínculo de la educación con lo social para modificar esa realidad vivida, investigada y reflexionada.

La perspectiva de educación social, existente en los procesos educativos que se adelantan en el Minuto de Dios, se unen a una comprensión no solo de la educación social, sino además de una pe- dagogía social, que en la Facultad de Educación se entiende como un aspecto sustentado en la praxis, lo que ha implicado el abordaje de lo que se ha denominado como pedagogía praxeológica y que se inserta en la contextualización de una interpretación de la educación social en tanto ésta es un aspecto integrador y característico de la propuesta del Minuto de Dios.

La pedagogía praxeológica no es un método pedagógico. Ella es más bien una visión, un ideal a conseguir y un marco integrador de la formación a ofrecer a los estudiantes y demás actores del proceso educativo. Quiere ser un marco conceptual integrador, que se adhiere a valores humanistas fundamentales, pero que invita tanto a los maestros como a los aprendices, a un proceso reflexivo y crítico sobre su propia práctica, en el marco de un real flexibilidad curricular. Ella busca coherencia y sinergia, pero no le teme al debate y la controversia. Ella exige compromiso y cuestionamiento continuo. Quiere guiar la formación inicial y permanente del profesional de la docencia y servir de apoyo a las acciones educativas, pero no pretende simplificar el quehacer educativo ni hacerlo de fácil acceso (Juliao, 2011, p. 1).

Se asegura que hablar de Uniminuto es hablar de praxeología y que ésta, como constructo, pretende generar en los estudiantes y maestros la lectura y reflexión de su quehacer, es decir, de su propia acción en los contextos, con el propósito de mejorar los procesos y las interrelaciones.

La formación integral del sujeto en todas sus dimensiones y un proyecto de vida asociado a la práctica de la responsabilidad social desde la sensibilidad crítica, para ver las problemáticas de las comunidades y con competencias adecuadas para enfrentar los retos personales y profesionales, son aspectos relevantes que desde la praxeología se hacen realidad en la vivencia educativa.

En ese orden de ideas, la praxeología constituye un proceso de concientización de los actos propios y sociales donde se integra la construcción de conocimiento que se pone en práctica a través de la validación de las experiencias y no simplemente de la teoría. El enfoque praxeológico es acertado para trabajar lo social porque permite la 
intervención de las comunidades y sus realidades, así como el análisis y acercamiento investigativo y desde allí la configuración de las acciones de intervención que a modo de afectaciones abordan sus necesidades.

¿Cuál es el rol que cumple el sujeto en esta relación de educación social y enfoque praxeológico? Según Juliao:

El sujeto del que se ocupa la Organización Minuto de Dios, en todas sus variantes es, esencialmente, un sujeto de recorridos sociales y culturales, resultado de los lugares que se le permiten y acepta ocupar, cuyo destino aparece, en cierto modo, ligado al destino de la organización porque de lo que se trata para el Minuto de Dios, en últimas, es del desarrollo humano y social de las personas y comunidades (2007, p. 224).

Ese reconocimiento del sujeto en sus condiciones cambiantes es el que caracteriza la opción de desarrollo de la propuesta de formación del Minuto de Dios. El análisis de las situaciones que impiden el desarrollo social equitativo ha permitido que la propuesta siente sus bases en la oportunidad de construcción de una sociedad justa, que parte de la conformación de comunidades organizadas, auto sostenibles y comprometidas con su propio desarrollo.

Hasta aquí se da por sentado que el trabajo del Minuto de Dios se ha desarrollado y planteado desde una perspectiva de reconocimiento de lo social en todas sus dimensiones, sobre todo teniendo en cuenta sus principios fundadores, la filosofía y misión de la obra del Padre García Herreros. Sin embargo, ¿cómo develar la forma como actualmente se interpreta y desarrolla la educación social dentro del Minuto de Dios?

Un acercamiento a esta pregunta se proporciona a partir del desarrollo del ejercicio de la investigación, entendida ésta como una forma de observar, interpretar y analizar los hechos, sucesos y acciones que dentro de un contexto determinado se gestan y le dan sentido a la acción, la significan y la resignifican en un particular acto de construcción permanente.
En esa línea, se plantea el desarrollo de un proyecto de investigación que como objetivo general parta por reconocer la manera como se concibe la educación social, buscando puntos de encuentro, distancias, coherencias e incoherencias, entre lo que se intuye y lo que se declara en los documentos institucionales existentes, pero también en lo que se refleja en las acciones formativas en los diversos escenarios de trabajo con los sujetos.

Así las cosas, surge como oportunidad la pregunta por la concepción que se tiene sobre educación social en los pregrados de la Facultad de Educación, en las Facultades de la sede principal de Uniminuto y en las instituciones de educación básica y media de la organización Minuto de Dios, como escenarios concretos de desarrollo de una propuesta de educación social instaurada desde hace ya varios años y que puede encontrar en la investigación una oportunidad para afianzarse, potenciarse o reestructurarse en busca de la coherencia en la vivencia de un modelo educativo.

Todo en una evidente necesidad de identificar la manera como, según Juliao,

El modelo educativo social implícito en la obra ayudará a convertir en realidad la utopía de la cohesión social y la inserción, de la democracia y la solidaridad, en la medida en que contribuye a terminar con la exclusión, al favorecer una participación ciudadana efectiva (2007, p. 224).

Se propone entonces, como alternativa, visualizar desde el análisis del entorno educativo inmediato que tiene la propuesta del Minuto de Dios en la educación superior, básica y media, el desarrollo de una educación de calidad, que ha optado por los menos favorecidos, quienes se dignifican a través de los procesos educativos y que, se espera, se comprometan a trabajar en pro de sus comunidades en el marco de un sentido amplio de la educación social.

$\mathrm{Al}$ respecto de la educación, según Juliao (2008), el Padre García Herreros la entendía como un proceso de integración individual y cultural de la persona a una comunidad; como un quehacer 
social que se prolonga a lo largo de la vida y que permite que las personas se vayan formando como individuos que viven en grupo y en sociedad, para desarrollarse integralmente e intervenir en la vida de la comunidad de la que hacen parte.

La premisa que ha acompañado el actuar formativo en el Minuto de Dios está soportada en la idea de la responsabilidad social que se adquiere desde el reconocimiento individual y el valor del rol que se tiene en un contexto social mediado por interrelaciones que transforman la acción de los sujetos, siendo la reflexión sobre dichas acciones lo que permite la construcción de sentidos de sociedad y de mundo.

Cabe entonces preguntarse: ¿Cómo el discurso de la educación social se relaciona con el enfoque praxeológico y éste a su vez con la pedagogía social? ¿Cuáles son los puntos de convergencia y cómo estos se ven reflejados en la propuesta educativa del Minuto de Dios? Los desarrollos planteados en el ejercicio de investigación guardan una amplia relación con estas preguntas y se visualizan en el marco de una revisión inicialmente del contexto internacional, en la línea de reconocer las raíces de la educación y pedagogía social, así como también del contexto nacional, en aras de identificar propuestas similares que partan o se unan a la visión educativa del Minuto de Dios.

Lo anterior debe unirse necesariamente al examen juicioso de los documentos institucionales de Uniminuto y de las instituciones educativas de básica y media de la Organización Minuto de Dios, a partir de la definición de unas categorías que permitan entender lo que se propone institucionalmente como alternativa de trabajo desde la perspectiva de educación social.

Sin embargo, el ejercicio de revisión documental debe complementarse con la observación directa de los contextos en sus dinámicas particulares, para lo cual será fundamental la visita a las instituciones educativas de básica y media del Minuto de Dios con dos propósitos esenciales: socializar la propuesta de investigación y motivar la participación en el proceso y documentar la experiencia con la aplicación de instrumentos de investigación in situ que recojan la voz de los actores, sus percepciones y sus proyecciones sobre lo que a la educación social respecta.

De acuerdo con esto, educación social, pedagogía social y pedagogía praxeológica como escenarios discursivos sobre los cuales es posible establecer relaciones significativas que permitan la interpretación de los aspectos particulares de una propuesta social, forjada sobre la perspectiva misional del Padre García Herreros, se constituyen en los referentes sobre los cuales el desarrollo investigativo estructura sus acciones en un marco para el desarrollo de la investigación que, como se ha dicho, parte del planteamiento de una necesidad de comprender la forma como se concibe la educación social y que se vincula con la oportunidad de adelantar acciones asociadas con: la revisión de documentos institucionales que, para el caso de la Facultad de Educación, corresponden a los proyectos curriculares de programa, el Proyecto Pedagógico de la Facultad, así como Proyecto Educativo Institucional de Uniminuto (PEI, versión 2013), el modelo educativo, el modelo de gestión curricular y el Documento General de Investigación. Finalmente, en cuanto a las instituciones educativas de básica y media, es importante revisar los proyectos educativos institucionales (PEI) y adelantar acciones de recolección de información in situ.

¿Cuáles pueden ser los resultados esperados de un desarrollo investigativo de este orden, que parte de la identificación de la realidad del contexto formativo del Minuto de Dios y a favor de reconocer la propuesta de educación social implícita en el mismo? Es posible advertir impactos que guardan relación fundamentalmente con los procesos de reconocimiento interno que las instituciones revisadas pueden tener de su propia propuesta de formación, ya que al visualizar las debilidades y fortalezas se podrán proponer, a partir de éstas, estrategias que promuevan el fortalecimiento y la divulgación de la propuesta.

Además, un ejercicio de investigación de este corte muy seguramente aportará nuevos

Polisemia No. 17, 70 - 75. Educación social en la Organización Minuto de Dios. Tras las huellas de un sueño. Bogotá, ISSN: 1900-4648. Enero - junio de 2014 
elementos para el análisis de la labor social que la Organización Minuto de Dios ha desarrollado desde hace varios años, concretamente desde los procesos de formación de los sujetos, la intervención que estudiantes y egresados hacen en comunidades que lo requieren y los procesos de transformación de las personas que se vinculan a este proyecto educativo y social.

Es posible además que se logre posicionar con mayor claridad la propuesta de formación social de Uniminuto como experiencia significativa, con mayor reconocimiento nacional e internacional por la coherencia y el aporte que realiza a la construcción del tejido social de un país que necesita urgentemente concientizarse sobre el valor social de sus gentes, el fortalecimiento de la equidad y la responsabilidad social, para lo que la participación en eventos es un aspecto importante como estrategia de divulgación y masificación de la propuesta de proyección social del Minuto de Dios.

\section{Referencias}

Briceño, S. (2013). Educación social en la Organización Minuto de Dios. Proyecto de investigación. III Convocatoria para el desarrollo y fortalecimiento de la investigación en Uniminuto. Documento propuesta.

Juliao, C. (2001a). Construcción de un modelo pedagógico alternativo a partir de la praxeología. Bogotá: Corporación Universitaria Minuto de Dios.

(2001b). La pedagogía praxeológica: Una teoria de la Práctica. Bogotá: Corporación Universitaria Minuto de Dios.

(2007). Educación Social: El Minuto de Dios: una experiencia y un modelo. Bogotá: Corporación Universitaria Minuto de Dios.
Finalmente, se considera la responsabilidad social en Uniminuto como un reto desde el que se aborda de manera comprometida la solución a los problemas que la sociedad está demandando. La interacción con las problemáticas en contextos reales consolidan un modelo basado en el encuentro de competencias sociales, por lo que es pertinente desarrollar este tipo de proyectos de investigación, que den lugar a la transformación social que busque fundamentalmente el encuentro con la equidad, la participación, la igualdad y la democracia.

Es así como esta investigación parte de la exploración de una dinámica de trabajo pensado y desarrollado desde el reconocimiento del sujeto en su individualidad, pero también en su condición social. El sello de Uniminuto sigue consolidándose como una propuesta alternativa de sociedad y de país, las acciones que se gesten para mejorar su reconocimiento y divulgación son apuestas dirigidas a resignificarla y potenciarla.

\footnotetext{
Uniminuto. Dirección de Planeación y Desarrollo. Sistema Universitario Uniminuto. Bogotá: Corporación Universitaria Minuto de Dios.
}

Pérez Serrano, G. (2003). Pedagogía SocialEducación Social: Construcción cientifica e intervención. Madrid: Narcea.

Petrus, A. (1997). Concepto de Educación social: En A. Petrus (Coord.), Pedagogía Social (pp. 9-39) Barcelona: Ariel. 